from the Navy, and resumed his duties at the Samaritan Hospital.

In the first half of the nineteenth century the mortality from surgical operations was high, and only the most daring of surgeons opened the abdominal cavity. In the majority of cases, death occurred from sepsis, and in the large metropolitan hospitals morbidity and mortality were highest from this cause. One well-recognized condition was the ovarian cyst, a slow-growing tumour.

Mr. Shepherd describes at some length the work of the early operators, the ovariotomists, both British and American, their limited successes and their failures through sepsis. By 1857 the operation was in disuse and was considered an unjustifiable one by many surgeons. Nevertheless, Wells developed this operation, his first success being on a woman of thirty-eight in 1858. He faithfully recorded his cases, and soon became famous for his masterly technique. Later, when Lister had introduced antisepsis into surgery, the mortality from ovariotomy was greatly diminished.

Wells had to face much hostility and opposition. Even when the success of his operation was established, attempts were made by Clay, Lawson Tait and others to challenge his priority. Wells met all these attacks with dignity and calmness. "Only an individual possessed of the strongest will and determination could have stood up to the opposition which he had to encounter." The account of these professional jealousies makes sad reading in regard to men who must have adopted the healing art in order to benefit mankind.

In the end the claims of Wells were fully vindicated. He was elected president of the Royal College of Surgeons for 1882-83, created a baronet and accorded international fame. He died of apoplexy on January $31,1897$.

Sir Frederick Treves wrote of Spencer Wells that he "by his determination succeeded in founding abdominal surgery as we know it", and also said that his work contributed to make surgery a precise science. In this biography Mr. Shepherd gives chapter and verse for these outstanding achievements.

\section{A. MacNalty}

\section{PHYSICS OF THE EAR}

\section{The Physics of the Ear}

(International Series of Monographs on Physics, Vol. 3.) By T. S. Littler. Pp. ix +378. (Oxford, London and New York: Pergamon Press, 1965.) $80 s$.

$\mathrm{D}$ T. S. LITTLER is well known to the medical and educational profession as the director of the Wernher Research Unit on Deafness. His book, The Physics of the Ear, contains fifteen chapters with supplementary sections giving mathematical treatment of physical data. As the title would suggest, the subjects of anatomy, physiology and measurements of hearing are dealt with from the point of view of the physicist rather than the clinician, who would wish a greater discussion on the application to various elinical states. The approach given in the book lays an excellent theoretical and practical basis for the clinician.

The subjects of hearing and deafness have captured the attention of physiologists especially during the past twenty years when experimental approaches have been possible due to the advances in techniques for investigating nerve physiology. Dr. Littler makes a very comprehensive and eritical survey of the literature to date and is to be specially commended for referring to the very early work both in Great Britain and the United States.

In the section on anatomy the most up-to-date data are described and discussed, with the possible exception that insufficient space has been given to the efferent pathways described by Rasmussen and to such work as that by Fex and Hernandez Péon. The work on the physiology of the ear during the past 20 years has been most exciting. Dr. Littler manages to convey the wealth of knowledge we have gained in this period in a careful analytical approach to the literature, bringing out the work of Von Békésy, Davis and his collaborators but paying respect to the early pioneers.

The book gives comprehensive coverage on both the physical and physiological aspects of thresholds of hearing with reference to auditory fatigue and adaptation-a subject with which the author is himself more particularly familiar in his research. The chapter on audiometry is covered rather from the aspects of the theories of testing hearing than from a detailed clinical application to varying pathologies. This is not a criticism of a book which is not intended to be primarily a clinical text-book.

The final chapter, on "Theories of Hearing", is a most valuable conclusion to the main body of the book. It is of interest to see that Dr. Littler in planning his own book has placed this subject last. Perhaps it is a reflexion of his own thinking, which has always placed greater emphasis on experimental data as his basis of thought and action. As throughout the book, this final chapter is dealt with most thoroughly and critically.

Dr. Littler's contribution to the standardization of audiometric threshold is universally recognized. In the chapter on audiometry he reports fully on his own work in this field. The chapter dealing with the alleviation of deafness bears the stamp of his own experience, as does the section describing the development of hearing aids. The detailed description of the development of the Medresco hearing aid will be of interest to the reader. The criticism that must be offered here is that there does not appear to have been sufficient differentiation between the congenitally and acquired deaf among children and adults. The possibility that congenitally deaf children will need a different type of hearing aid from the deafened adult does not appear to have been given sufficient critical analysis.

Throughout, the book is writton in a clear, readable style. Dr. Littler manages in his lucid way to bring together the many facets from the old and the new and weld together a coherent story, giving each part a perspective which will help the reader to gain an insight into the development of audiology. The book is to be highly recommended to those entering this field as well as to the experienced anatomist, physiologist and clinician. It is a book which offers a fund of information, including a valuable reference section. The publishers ought also to be congratulated on this publication. I. G. TAYLOR

\section{MAMMALIAN POPULATIONS}

\section{Physiological Mammalogy}

Edited by William V. Mayer and Richard G. Van Gelder.

Vol. 1: Mammalian Populations. Pp. xii +381 . 868 . Vol. 2: Mammalian Reactions to Stressful Environments. Pp. xii + 326. 92s. (New York: Academic Press, Inc.; London: Academic Press, Inc. (London), Ltd., 1963 and 1965.)

DOPULATIONS of small mammals (that is, rodents and insectivores approximately up to the size of the brown rat, Rattus norvegicus) have attracted the attention of ecologists for many years and, especially since the end of the First World War, much labour has been spent on measuring their population dynamics and putting forward theories concerning the natural regulation of their numbers. Their importance lies first in their notably wide distribution and abundance as primary and, to a lesser extent, secondary consumers in most animal communities; secondly, in the wide ranges within which their numbers fluctuate and in the cyclic nature, especially in Arctic and sub-Arctic habitats, of these fluctuations. The pervasive nature of this behaviour and the frequent economic 